\title{
Immobilized Inocula of White-Rot Fungi Accelerate both Detoxification and Organic Matter Transformation in Two-Phase Dry Olive-Mill Residue
}

\author{
Inmaculada SAmpedro, ${ }^{\dagger},+$ Tomas CaJThaml, ${ }^{\S}$ Sara Marinari, ${ }^{\dagger}$ \\ Silvia Rita Stazi, ${ }^{\dagger}$ Stefano Grego,${ }^{\dagger}$ Maurizio Petruccioli ${ }^{\dagger}$ \\ Federico Federici, ${ }^{\dagger}$ and Alessandro D’Annibale ${ }^{*} \dagger$

\begin{abstract}
†Department of Agrobiology and Agrochemistry, University of Tuscia, Via S. Camillo de Lellis snc, I-01100 Viterbo, Italy, "Departamento Microbiología, Estación Experimental del Zaidín, CSIC, Prof. Albareda 1, E-18008 Granada, Spain, and ${ }^{\S}$ Institute of Microbiology, Academy of Sciences of the Czech Republic, Videnská 1083, 14220 Prague 4, Czech Republic
\end{abstract}

\begin{abstract}
The potential use for agronomic purposes of dry olive-mill residue (DOR), solid waste from the olive oil two-phase extraction process, might be impaired by its phytotoxicity. Although fungal treatments can detoxify DOR, long times are required for these processes. The objective of this study was to assess whether the addition of immobilized fungal inocula to DOR might improve colonization rates, thus reducing the time necessary for its detoxification and bioconversion. Inocula of Panus tigrinus CBS 577.79 and Phlebia sp. DABAC 9 immobilized on either chopped maize stalks or polyurethane sponge (PS) led to higher removals of both phenols and phytotoxicity from DOR than free inocula after 4 weeks of incubation. Best dephenolization (85\%) was with PS-immobilized Phlebia sp., the use of which reduced germinability inhibition of Lepidium sativum and Lactuca sativa by 80 and $71.4 \%$, respectively. Regardless of the type of inoculant, a low degree of humification was obtained.
\end{abstract}

KEYWORDS: White-rot fungi; immobilized inocula; phenols; dry olive-mill residue; phytotoxicity; thermochemolysis

\section{INTRODUCTION}

Large amounts of both liquid and solid organic wastes are annually produced by the olive oil extraction process, the seasonality of which leads to dramatic accumulation over a restricted time period. Environmental problems, formerly confined within the Mediterranean area and due to both improper storage and disposal procedures, are rapidly evolving in other countries such as Australia, Chile, and the United States. At the beginning of the 1990s, an innovative two-phase extraction process (TPEP) was introduced in Spain and in Croatia, where this technology rapidly extended to about $90 \%$ of the olive oil mills ( 1 ). The TPEP generates a liquid phase (olive oil) and a water-rich solid organic waste (alpeorujo), which is dried and extracted with solvents to obtain an extra yield of oil and the dry olive-mill residue (DOR). It has been estimated that the annual production of DOR in Spain approaches 4 million tons (2). Among the possible strategies of the two-phase olive-mill wastes upgrading, much emphasis has been given to their agronomic use after composting ( 1 ). However, these wastes exhibit peculiar physical and chemical properties that hinder the success of the biological approach; both the high moisture content and the dough-like texture limit gaseous exchanges, thus slowing the process (3). The preponderance of plant cell wall macromolecules (i.e., lignin, cellulose, and hemicellulose) associated with both a relatively low amount

*Corresponding author [Telephone: + 39-(0)761357368; Fax: + 39(0)-761357242; E-mail: dannib@unitus.it]. of nitrogen $(0.7-1.8 \%)$ and the presence of antimicrobial compounds makes its composting slower (from 28 to 40 weeks) than that of other lignocellulosic wastes $(3,4)$.

DOR has a high concentration of organic matter (OM), which also includes toxic compounds, capable of inhibiting microbial growth (5) and germination and vegetative growth in plants (6). Because DOR toxicity has been mainly ascribed to phenols $(2,7)$, the use of ligninolytic fungi capable of degrading such compounds (6) can be an adequate approach for upgrading the waste. White-rot fungi (WRF) have been shown to remove phenols from DOR, although detoxification required long colonization times (7).

For this reason, the main objective of this study was to assess whether the addition of immobilized inocula of WRF to DOR might improve the colonization rate and reduce times required to detoxify the waste. In the present study, both natural and synthetic carriers, namely, chopped maize stalks (CMS) and polyurethane sponge (PS), were used. Although use of the latter carrier cannot be envisaged at the field scale, PS was used in this study because, besides being a valuable immobilization support for fungi, it is totally inert, thus allowing possible comparative discrimination between protective and trophic effects.

Panus tigrinus CBS 577.79 and Phlebia sp. DABAC 9, previously selected on the basis of their colonization rate on agar media added with DOR, were inoculated on CMS or PS and 7-day-old colonized carriers subsequently added to DOR. A particular focus was given in this study to the determination of the impact of the selected fungi on the relative abundances of 
both labile and stabilized carbon fractions in DOR, as opposed to the majority of investigations on the fungal conversion of this waste (6). In addition, possible structural changes in the waste that had undergone fungal treatment were investigated by pyrolysis with tetramethylammonium hydroxide followed by gas chromatography mass-spectrometry (TMAH-Py-GC MS) and compared with corresponding abiotic controls.

\section{MATERIALS AND METHODS}

Materials and Preparation of Immobilization Supports. DOR, withdrawn from an olive oil manufacturer (Sierra Sur S.A., Granada, Spain), was stored at $-20^{\circ} \mathrm{C}$ until used. Its chemical composition was as follows: $\mathrm{pH}, 5.13$; total organic carbon, $49.5 \%$; total nitrogen, $2.28 \%$; total phosphorus, $0.21 \%$; lignin, $24.7 \%$; cellulose, $18 \%$; hemicellulose, $12.8 \%$; total phenols, $3.18 \%$; total lipids, $0.2 \%$; ashes, $9.2 \%$. The most abundant elements in DOR were $\left(\mathrm{g} \mathrm{kg}^{-1}\right)$ potassium, 30.5; calcium, 13.6; magnesium, 3.8; iron, 1.1; sodium, 0.17; copper, 0.07; zinc, 0.06; and manganese, 0.04 . PS cubes, $0.5 \mathrm{~cm}$ width each, were rinsed with water in a $1: 20(\mathrm{w} / \mathrm{v})$ ratio and autoclaved $\left(121^{\circ} \mathrm{C}\right.$ for $\left.20 \mathrm{~min}\right)$ twice prior to their use. Maize stalks were chopped into approximately $0.5 \mathrm{~cm}$ pieces and sieved. Hydroxytyrosol, oleuropein, and luteolin standards for chromatography were from Extrasynthese (Lyon, France), whereas the remaining standards were from Aldrich (Milan, Italy).

Organisms and Inoculum Preparation. Panus tigrinus (CBS 577.79) and Phlebia sp. (DABAC 9) were maintained at $4{ }^{\circ} \mathrm{C}$ and routinely subcultured every month on potato dextrose agar slants. Fungal inocula were prepared as reported elsewhere (8). Five milliliters of the inoculum (ca. $50 \mathrm{mg}$ of $\mathrm{dw}$ ) was aseptically added to $50 \mathrm{~g}$ of sterilized supports and incubated at $28^{\circ} \mathrm{C}$ for 7 days.

Sample Preparation and Fungal Treatment. Deionized water was added to DOR to adjust the moisture content to $25 \%(\mathrm{w} / \mathrm{w})$ prior to sterilization $\left(120^{\circ} \mathrm{C}\right.$ for $\left.20 \mathrm{~min}\right)$. Then, either free mycelium ( $65 \mathrm{mg}$ of dw) or colonized solid supports (2.5 and $0.24 \mathrm{~g}$ of CMS and PS, respectively), were covered with $17.5 \mathrm{~g}$ of DOR. The amounts of either free or immobilized mycelial biomass to which the waste was added were normalized on the basis of the same initial chitin content $(5 \mathrm{mg})$. Solid-state cultures on DOR were carried out at $28^{\circ} \mathrm{C}$ in the dark under stationary conditions for 30 days. Non-inoculated and sterilized DOR samples were prepared and incubated as above and will be referred to as abiotic controls from here onward. In addition, biotic controls were prepared by mixing in a 10:1 ratio (w/w) sterilized DOR with a sandy-loamy soil, the physicochemical properties and microbial density of which were reported elsewhere (8). All experiments were carried out in triplicate.

Analytical Assays. Samples were incinerated at $600{ }^{\circ} \mathrm{C}$ for $12 \mathrm{~h}$, and $\mathrm{OM}$ was obtained by subtracting ash content from the whole sample weight. OM losses ( $\%$ ) were calculated from the ash contents in the waste at start $\left(X_{1}\right)$ and in either fungal-treated DOR or corresponding incubation controls $\left(X_{2}\right)$ according to eq $1(7)$ :

$$
\text { OM losses }(\%)=100-\frac{\left[X_{1} \times\left(100-X_{2}\right)\right]}{\left[X_{2} \times\left(100-X_{1}\right)\right]} \times 100
$$

Total extractable carbon (TEC) was extracted by mechanical shaking for $48 \mathrm{~h}$ at $65^{\circ} \mathrm{C}$ with $0.1 \mathrm{M} \mathrm{NaOH}$ plus $0.1 \mathrm{M} \mathrm{Na}_{2} \mathrm{P}_{4} \mathrm{O}_{7}$ under $\mathrm{N}_{2}$ atmosphere and using a 1:50 solid/liquid ratio. The suspension was then centrifuged (8000g; $20 \mathrm{~min}$ ) and the supernatant filtered through a $0.8 \mu \mathrm{m}$ membrane (Millipore, Danvers, MA). Humic acid carbon $\left(\mathrm{C}_{\mathrm{HA}}\right)$ was precipitated from the filtrate by adding $\mathrm{H}_{2} \mathrm{SO}_{4}$ up to $\mathrm{pH} 2.0$, then centrifuging as above, and the pellet was collected and stored at $4{ }^{\circ} \mathrm{C}(9)$. The supernatant $(25 \mathrm{~mL})$ was loaded onto a small column $(10 \mathrm{~mL})$ packed with polyvinylpolypyrrolidone and previously equilibrated with $5 \mathrm{mM} \mathrm{H}_{2} \mathrm{SO}_{4}$; the retained fraction made of fulvic acid carbon $\left(\mathrm{C}_{\mathrm{FA}}\right)$ was then eluted by $0.1 \mathrm{M} \mathrm{NaOH}$ and collected into a centrifuge tube (9). Total organic carbon (TOC), TEC, $\mathrm{C}_{\mathrm{HA}}$, and $\mathrm{C}_{\mathrm{FA}}$ were determined according to the dichromate oxidation method as previously reported (7). The loss of $\mathrm{C}$ throughout incubation was calculated according to eq 2 (4)

$$
\text { TOC losses }(\%)=100-\frac{\left[X_{1} C_{2}\right]}{\left.\left[X_{2} C_{1}\right)\right]} \times 100
$$

where $X_{1}$ and $X_{2}$ and $C_{1}$ and $C_{2}$ are ash and TOC concentrations, respectively, in the waste at start and in either abiotic controls or related fungal treatments. Degree of humification (DH), humification ratio (HR), and humification index (HI) were calculated from the following ratios, respectively:

$$
\begin{aligned}
\mathrm{DH} \% & =\frac{C_{\mathrm{HA}}+C_{\mathrm{FA}}}{\mathrm{TEC}} \times 100 \\
\mathrm{HR} \% & =\frac{C_{\mathrm{HA}}+C_{\mathrm{FA}}}{\mathrm{TOC}} \times 100 \\
\mathrm{HI} & =\frac{C_{\mathrm{HA}}}{\mathrm{TOC}} \times 100
\end{aligned}
$$

Total N, P, K, Fe, Mn, Cu, and $\mathrm{Zn}$ contents of the DOR were determined as reported elsewhere (7). Acetone/water-soluble phenols (AWSP) were extracted from $2 \mathrm{~g}$ of DOR with $20 \mathrm{~mL}$ of acetone/acidified water at $\mathrm{pH} 3.0(50: 50, \mathrm{v} / \mathrm{v})$ for $24 \mathrm{~h}$ at $4{ }^{\circ} \mathrm{C}$ and determined using tyrosol as the standard (7). Dephenolization efficiency (DE) was calculated by normalizing the amount of phenols removed to the same fungal biomass ( $\mathrm{g}$ of phenols removed $\mathrm{g}^{-1}$ of chitin). On the other hand, the dephenolization selectivity (DS) was calculated by the ratio of removed phenols to organic matter depleted.

Chromatographic and TMAH-Py-GC MS Analyses. Gas chromatographic-mass spectrometric (GC-MS) analyses were performed on DOR ethyl acetate residues derivatized with $N, O$-bis(trimethylsilyl) trifluoroacetamide in pyridine as previously reported (10). Identification of aromatic compounds was based on comparison with retention times and mass spectra of pure standards and comparison of the mass spectra with those in the NIST92 and NIST95 libraries.

Reversed-phase high-performance liquid chromatography (RPHPLC) was used to quantify the degradation of the main aromatic compounds (11).

TMAH-Py-GC MS analyses were performed as previously described (12). Pyrolysis products were identified both by comparing mass spectra with data in the NIST02 library and by interpreting the fragmentation pattern. Data are the mean of triplicate runs, and the percentages of pyrolysis products were calculated from the relative areas of the peaks after recalculation according to the exact weight of samples. With the notable exception of pyrolysis products derived from carbohydrates, the coefficient of variation of the most abundant peaks was lower than $15 \%$. Individual fragments detected after pyrolysis were divided into the following four main groups according to their origin: lignin-related compounds (L), carbohydrates (C), fatty acids (FA), and nitrogen-containing compounds $(\mathrm{N})$. When possible, fragments belonging to the first group were assigned to lignin basic structures: $\mathrm{P}, p$-hydroxyphenyl; $\mathrm{G}$, guaiacyl (3-methoxy-4-hydroxyphenyl); and S, syringyl (3,5-dimethoxy-4hydroxyphenyl). The relative percent abundances of $\mathrm{P}, \mathrm{G}$, and $\mathrm{S}$ subunits were calculated by dividing the areas of peaks pertaining to each subunit either by the total area of pyrograms $(\mathrm{P} \%, \mathrm{G} \%, \mathrm{~S} \%)$ or by their sum $\left(\mathrm{P}_{\mathrm{n}} \%, \mathrm{G}_{\mathrm{n}} \%, \mathrm{~S}_{\mathrm{n}} \%\right)$. The syringyl/guaiacyl ratio $(\mathrm{S} / \mathrm{G})$ and guaiacyl and syringyl acid/aldehyde ratios, namely, $(\mathrm{Ad} / \mathrm{Al})_{\mathrm{G}}$ and $(\mathrm{Ad} / \mathrm{Al})_{\mathrm{S}}$, were calculated as described by Vane et al. (13).

Fungal Growth and Metabolic Activity. The extent of fungal biomass was indirectly estimated by the chemical determination of the chitin content in the solid substrate as previously described (7). Growth was also assessed subjectively on a $0-10$ scale, with 0 meaning absence of growth and 10 complete hyphal colonization of the surface of the solid substrate (14). The index of metabolic activity in axenic fungal cultures, namely, the fungal metabolic index (FMI), was calculated from the mass ratio of organic matter losses to fungal biomass and expressed as grams of substrate consumed per gram of glucosamine.

Enzyme Assays. Extracellular enzymes were extracted from DOR, dialysis-filtered, and 20-fold concentrated as previously reported (8). Manganese peroxidase $(\mathrm{MnP})$ and laccase activities were assayed as described by D'Annibale et al. (10). The monophenolase activity of tyrosinase, that is, the hydroxylation of monophenols to $o$-diphenols, was assayed according to the method of Espín et al. (15). Appropriate controls were performed with heat-denatured extracts. Enzyme activities were expressed as nanokatals per gram of DOR. 
Table 1. Fungal Growth Indices, Organic Matter (OM) and Total Organic Carbon (TOC) Losses, Fungal Metabolic Index (FMI) in DOR at Start (DOR $\left.t_{0}\right)$, Its Biotic Control (DOR-BC), and the Same Waste That Had Been Incubated with P. tigrinus and Phlebia sp. Added either in Free Form (DOR-Ptand DOR-Psp., Respectively) or Previously Immobilized onto Chopped Maize Stalks (DOR-Pt-CMS and DOR-Psp-CMS, Respectively) or Polyurethane Sponge (DOR-Pt-PS and DOR-Psp-PS, Respectively) and in Abiotic Controls (AC-CMS and AC-PS)

\begin{tabular}{|c|c|c|c|c|c|}
\hline \multirow[b]{2}{*}{ sample } & \multicolumn{2}{|c|}{ growth index } & \multirow[b]{2}{*}{ OM loss ${ }^{a}(\%)$} & \multirow[b]{2}{*}{ TOC $\operatorname{loss}^{a}(\%)$} & \multirow[b]{2}{*}{$\mathrm{FMI}^{a}$} \\
\hline & subjective $^{a}(0-10)$ & $\operatorname{chitin}^{a}(\mathrm{mg} / \mathrm{g})$ & & & \\
\hline $\mathrm{DOR} t_{0}$ & $\mathrm{nd}^{b}$ & $0.2 \mathrm{~A}$ & nd & nd & $\mathrm{nc}^{\mathrm{c}}$ \\
\hline DOR-BC & nd & $0.4 \mathrm{~B}$ & $7.0 \mathrm{~B}$ & $8.5 \mathrm{C}$ & $\mathrm{nc}$ \\
\hline DOR-AC-CMS & nd & $0.1 \mathrm{~A}$ & $4.0 \mathrm{~A}$ & $5.8 \mathrm{~B}$ & $\mathrm{nc}$ \\
\hline DOR-AC-PS & nd & $0.1 \mathrm{~A}$ & $3.7 \mathrm{~A}$ & $4.9 \mathrm{~A}$ & $\mathrm{nc}$ \\
\hline DOR-Pt & 3 & $0.7 \mathrm{C}$ & $8.3 B$ & $10.5 \mathrm{D}$ & $118.3 \mathrm{~B}$ \\
\hline DOR-Psp & 4 & $0.7 \mathrm{C}$ & $7.2 \mathrm{~B}$ & $8.4 \mathrm{C}$ & $109.9 \mathrm{~B}$ \\
\hline DOR-Pt-CMS & 8 & $1.5 \mathrm{D}$ & $24.3 E$ & $24.1 \mathrm{G}$ & $158.7 \mathrm{C}$ \\
\hline DORPsp-CMS & 8 & $1.4 \mathrm{D}$ & $32.5 \mathrm{~F}$ & $35.0 \mathrm{H}$ & $235.8 \mathrm{D}$ \\
\hline DOR-Pt-PS & 8 & $1.4 \mathrm{D}$ & $16.9 \mathrm{D}$ & $19.5 \mathrm{~F}$ & $117.2 \mathrm{~B}$ \\
\hline DOR-Psp-PS & 7 & $1.5 \mathrm{D}$ & $11.4 \mathrm{C}$ & $16.1 \mathrm{E}$ & $78.4 \mathrm{~A}$ \\
\hline
\end{tabular}

${ }^{a}$ Data are the mean of three independent experiments: column means followed by the same upper case letter are not significantly different $(P \leq 0.05) .{ }^{b}$ nd, not determined. ${ }^{c} \mathrm{nc}$, not calculated.

Table 2. Acetone/Water-Soluble Phenols (AWSP) and Ethyl Acetate-Extractable Phenols (EAEP), Dephenolization Efficiency and Selectivity in DOR at Start (DOR $t_{0}$ ), Its Biotic Control (DOR-BC), and the Same Waste That Had Been Incubated with P. tigrinus and Phlebia sp. Added either in Free Form (DOR-Pt and DOR-Psp, Respectively) or Previously Immobilized onto Chopped Maize Stalks (Pt-CMS and Psp-CMS, Respectively) or Polyurethane Sponge (Pt-PS and Psp-PS, Respectively) and in the Respective Abiotic Controls (AC-CMS and AC-PS)

\begin{tabular}{lcccc}
\hline \multicolumn{1}{c}{ sample } & AWSP $^{a}\left(\mathrm{mg} \mathrm{g}^{-1}\right)$ & $\operatorname{EAEP}^{a}\left(\mathrm{mg} \mathrm{g}^{-1}\right)$ & dephenolization efficiency & dephenolization selectivity \\
\hline DOR $t_{0}$ & $41.9 \mathrm{D}$ & $11.7 \mathrm{E}$ & $\mathrm{nc}$ & $\mathrm{nc}$ \\
DOR-BC & $35.9 \mathrm{D}$ & $10.4 \mathrm{D}$ & $\mathrm{nc}$ & $\mathrm{nc}$ \\
DOR-AC-CMS & $39.4 \mathrm{D}$ & $11.6 \mathrm{E}$ & $\mathrm{nc}$ & $\mathrm{nc}$ \\
DOR-AC-PS & $37.4 \mathrm{D}$ & $12.0 \mathrm{E}$ & $\mathrm{nc}$ \\
DOR-Pt & $27.4 \mathrm{C}$ & $7.7 \mathrm{C}$ & $20.7 \mathrm{~A}$ & $0.17 \mathrm{C}$ \\
DOR-Psp & $23.8 \mathrm{~B}$ & $6.7 \mathrm{C}$ & $27.9 \mathrm{C}$ & $0.25 \mathrm{E}$ \\
DOR-Pt-CMS & $6.0 \mathrm{~A}$ & $1.2 \mathrm{~B}$ & $23.4 \mathrm{~B}$ & $0.15 \mathrm{~B}$ \\
DOR-Psp- CMS & $5.3 \mathrm{~A}$ & $26.5 \mathrm{BC}$ & $0.11 \mathrm{~A}$ \\
DOR-Pt-PS & $6.2 \mathrm{~A}$ & $0.6 \mathrm{~A}$ & $24.8 \mathrm{~B}$ & $0.21 \mathrm{C}$ \\
DOR-Psp-PS & $5.8 \mathrm{~A}$ & $1.0 \mathrm{~B}$ & $24.7 \mathrm{~B}$ & $0.32 \mathrm{D}$ \\
\hline
\end{tabular}

${ }^{a}$ Data are the mean of three independent experiments: column means followed by the same upper case letter are not significantly different $(P \leq 0.05) .{ }^{b} \mathrm{nc}$, not calculated.

Phytotoxicity Assays. The phytotoxicity of DOR, at start or differently treated, was determined as described by Zucconi et al. (16). Seventy seeds of either Lepidium sativum or Lactuca sativa were placed, in triplicate, in $9 \mathrm{~cm}$ diameter Petri dishes containing sterilized quartz sand mixed with $5 \%(\mathrm{w} / \mathrm{w})$ DOR and incubated in the dark at $25^{\circ} \mathrm{C}$ for $48 \mathrm{~h}$. Control experiments were conducted in the absence of the waste. Germinated seeds were counted and radicle growth measured. Percent inhibition ( $\mathrm{\%} \%$ ) of either germinability or radicle elongation was calculated from eq 6

$$
\mathrm{I} \%=\left(1-\frac{G}{G_{\mathrm{c}}}\right) \times 100
$$

where $G$ is the number of either germinated seeds or radicle length observed in the presence of either fungal-treated DOR or abiotic controls and $G_{\mathrm{c}}$ the same parameters in the absence of the waste.

Statistical Analysis. Multiple pairwise comparisons were performed by the Tukey test. Thermochemolysis data were also subjected to principal component analysis (PCA) by the use of the Simca-P 8.0 software (Umetrics, Umea, Sweden). The possible presence of either moderate or strong outliers in observations was checked by the squared prediction errors and hotelling $\left(T^{2}\right)$ of $t$ scores, respectively (17). For both ANOVA and PCA, percent data were normalized by arcsin of the square root transformation.

\section{RESULTS}

Effect of the Carrier on both Mycelial Growth and Metabolic Activity on DOR. The white and yellowish mycelia of P. tigrinus and Phlebia sp., respectively, became visible at 2 weeks after inoculation but, at the end of the set incubation time, colonization of the substrate was not complete as assessed by both subjective growth index and chitin content (Table 1). By contrast, both fungi added to DOR in immobilized form exhibited rapid growth on the waste, and colonization of the solid substrate was extensive after 4 weeks. The fungal growth was not significantly affected by the inoculum carrier; the chitin contents of the waste colonized by the two fungi were rather similar (Table 1).

Despite the large similarities in the amount of growth, the bioconversion capabilities of the two immobilized fungi were markedly affected by the type of carrier, as indicated by both $\mathrm{OM}$ and TOC losses. Phlebia sp. was more affected by the type of carrier, leading to the highest (32.5\%) and lowest (11.4\%) OM losses when immobilized onto CMS and PS, respectively (Table 1). Moreover, CMS proved to be a better support than PS for P. tigrinus, leading to higher extents of both OM and TOC losses $(24.3 \pm 1.2$ vs $16.9 \pm 0.5$, respectively, and $24.1 \pm 0.8$ vs $19.5 \pm 0.4$, respectively). The FMI values were similar in DOR inoculated with free mycelia of the two fungi. By contrast, Phlebia sp. was greatly affected by the inoculum carrier, resulting in the highest and lowest FMI values with CMS and PS (235.8 vs 78.4, respectively) (Table $\mathbf{1}$ ).

Dephenolization of DOR and Production of Extracellular Phenoloxidizing Enzymes. The AWSP content of the waste (i.e., $41.9 \mathrm{~g} \mathrm{~kg}^{-1}$ of DOR) did not change in both abiotic controls, whereas about $14 \%$ dephenolization was detected in the biotic control (Table 2). AWSP percent removals in DOR that had been incubated with free mycelia of $P$. tigrinus and Phebia sp. were 36 and $43 \%$, respectively; by contrast, the extent of removal was significantly higher with both immobilized fungal inocula. In fact, AWSP were depleted from DOR by about $85 \%$ by both CMSand PS-immobilized $P$. tigrinus. Similar removals (i.e., $87 \%$ ) were 
Table 3. Initial Concentrations of Ethyl Acetate-Extractable Aromatic Compounds and Percent Removals of Each Compound Observed in DOR That Had Been Colonized by Panus tigrinus or Phlebia sp. Added either in Free Form (NS) or Previously Immobilized onto Chopped Maize Stalks (CMS) or Polyurethane Sponge $(\mathrm{PS})^{a}$

\begin{tabular}{|c|c|c|c|c|c|c|c|}
\hline \multirow[b]{3}{*}{ compound } & \multirow[b]{3}{*}{ initial concn (mmol/kg) } & \multicolumn{6}{|c|}{$\%$ removal $^{b}$} \\
\hline & & \multicolumn{3}{|c|}{ Panus tigrinus } & \multicolumn{3}{|c|}{ Phlebia sp. } \\
\hline & & NS & CMS & PS & NS & CMS & PS \\
\hline protocatechuic acid 1 & 0.2 & 55.1 & 95.0 & 97.0 & 58.9 & 97.7 & 100 \\
\hline hydroxytyrosol 2 & 18.0 & 29.6 & 93.6 & 94.9 & 37.7 & 98.2 & 99.5 \\
\hline catechol 3 & 3.8 & 62.0 & 93.1 & 88.9 & 70.3 & 90.7 & 93.6 \\
\hline tyrosol 4 & 6.9 & 36.2 & 80.9 & 96.4 & 48.7 & 85.0 & 89.4 \\
\hline 3,4-dihydroxymandelic acid 5 & 1.8 & 60.0 & 100 & 100 & 68.0 & 100 & 100 \\
\hline vanillic acid 6 & 4.0 & 68.9 & 84.7 & 87.7 & 69.6 & 97.0 & 98.0 \\
\hline syringic acid 7 & 2.3 & 0.0 & 0.0 & 45.0 & 65.5 & 53.0 & 54.8 \\
\hline p-coumaric acid 8 & 1.4 & 47.0 & 35.0 & 14.3 & 53.0 & 91.1 & 96.8 \\
\hline p-methoxyphenylacetic acid $\mathbf{9}$ & 0.8 & 0.0 & 67.6 & 65.5 & 0.0 & 81.9 & 80.2 \\
\hline 3,4,5-trimethoxybenzoic acid 10 & 0.6 & 0.0 & 42.3 & 89.9 & 0.0 & 55.5 & 62.0 \\
\hline luteolin 11 & 0.4 & 0.0 & 97.0 & 97.0 & 0.0 & 95.0 & 98.0 \\
\hline
\end{tabular}

${ }^{a}$ Arabic numbers have been assigned to each compound in order of increasing retention time $\left(t_{\mathrm{R}}\right): \mathbf{1}, 10.11 \mathrm{~min} ; \mathbf{2}, 10.6 \mathrm{~min} ; \mathbf{3}, 13.9 \mathrm{~min} ; \mathbf{4}, 15.5 \mathrm{~min} ; \mathbf{5}, 16.9 \mathrm{~min} ; \mathbf{6}, 17.6 \mathrm{~min} ; \mathbf{7}$, $19.2 \mathrm{~min} ; \mathbf{8}, 24.0 \mathrm{~min} ; \mathbf{9}, 25.9 \mathrm{~min} ; \mathbf{1 0}, 29.9 \mathrm{~min} ; \mathbf{1 1}, 41.3 \mathrm{~min}$. ${ }^{b}$ Data are the mean of triplicate runs, and the relative standard deviation was $\leq 8 \%$.

attained with DOR that had been incubated with both CMS and PS-immobilized Phlebia sp. Despite the large differences between free and immobilized mycelia in the overall amounts of phenols removed, it was found that DE values were highest in DOR incubated with both free and CMS-immobilized Phlebia sp. (27.9 and $26.5 \mathrm{~g}$ of phenols removed $\mathrm{mg}^{-1}$ of chitin, respectively). On the other hand, DS values showed that the highest and lowest selectivities were observed with PS- and CMS-immobilized Phlebia sp. (0.32 and 0.11, respectively) (Table 2).

Both GC-MS and reversed-phase HPLC analyses of ethyl acetate DOR extracts led to the identification of 11 aromatic compounds (Table 3). Compounds $\mathbf{2}$ and $\mathbf{4}$ were by far the most abundant aromatic components in ethyl acetate extracts (18 and $6.9 \mathrm{mmol} \mathrm{kg}{ }^{-1}$, respectively). However, significant concentrations of the substituted benzoic acids $\mathbf{1 , 6}$, and 7 and the cinnamic acid derivative 8 were detected $\left(0.2,4.0,2.3\right.$, and $1.4 \mathrm{mmol} \mathrm{kg}^{-1}$, respectively).

Low laccase levels $\left(0.2 \mathrm{nkatal} \mathrm{g}^{-1}\right)$ were detected in the biotic control (Table 4). In DOR that had been incubated with free mycelium of Phlebia sp., both laccase and $\mathrm{MnP}$ activities were found (2.1 and $4.6 \mathrm{nkatal}^{-1}$, respectively), whereas in P. tigrinus cultures only the former was detected. In DOR incubated with PS-immobilized fungi, both laccase and monophenolase activities were higher than with CMS-immobilized fungi. Regardless of the type of carrier, MnP was detected only with PS-immobilized Phlebia sp. (46.3 nkatal $\mathrm{g}^{-1}$ DOR).

Fungal Removal of Phytotoxicity from DOR. Both germinability and radicle elongation of Lactuca sativa and Lepidium sativum were suppressed in the presence of $5 \%$ DOR, thus showing the high phytotoxicity of the waste. These toxic effects were not significantly removed in either abiotic and biotic controls of DOR (Figure 1) and were largely evident in the waste that had been inoculated with free mycelia of both fungi.

Phytotoxicity toward Lepidium sativum was generally attenuated in the waste that underwent incubation with immobilized fungal inocula. Best results were obtained with PS-immobilized Phlebia sp.: inhibition of germinability and radicle elongation amounted to 20 and $2.8 \%$, respectively. By contrast, $P$. tigrinus was unable to mitigate the waste phytotoxicity toward L. sativa, regardless of the use of free or immobilized inocula. With this plant, the lowest inhibition of germinability $(19.6 \%)$ was observed in the waste treated with CMS-immobilized Phebia sp. (Figure 1A).

Regardless of the treatment typology, germinability of both plants plotted versus the absolute amounts of added phenols
Table 4. Laccase, Mn-Dependent Peroxidase (MnP), and Monophenolase Activities in DOR at Start (DOR $t_{0}$ ), Its Biotic Control (DOR-BC), and the Same Waste That Had Been Incubated with P. tigrinus and Phlebia sp. Added either in Free Form (DOR-Ptand DOR-Psp, Respectively) or Previously Immobilized onto Chopped Maize Stalks (Pt-CMS and Psp-CMS, Respectively) or Polyurethane Sponge (Pt-PS and Psp-PS, Respectively) and in the Relative Abiotic Controls (AC-CMS and AC-PS)

\begin{tabular}{llll}
\hline & \multicolumn{3}{c}{ enzyme activity ${ }^{a}$ (nkatal g ${ }^{-1}$ of DOR) } \\
\cline { 2 - 4 } \multicolumn{1}{c}{ sample } & laccase & MnP & monophenolase \\
\hline DOR to $_{\text {DOR-BC }}$ & $\mathrm{nd}^{\mathrm{b}}$ & $\mathrm{nd}$ & $\mathrm{nd}$ \\
DOR-AC-CMS & $0.2 \mathrm{~A}$ & $\mathrm{nd}$ & $\mathrm{nd}$ \\
DOR-AC-PS & $\mathrm{nd}$ & $\mathrm{nd}$ & $\mathrm{nd}$ \\
DOR-Pt & $\mathrm{nd}$ & $\mathrm{nd}$ & $\mathrm{nd}$ \\
DOR-Psp & $1.6 \mathrm{C}$ & $\mathrm{nd}$ & $\mathrm{nd}$ \\
DOR-Pt-CMS & $2.1 \mathrm{C}$ & $4.6 \mathrm{~A}$ & $\mathrm{nd}$ \\
DOR-Psp-CMS & $7.7 \mathrm{D}$ & $\mathrm{nd}$ & $0.6 \mathrm{~A}$ \\
DOR-Pt-PS & $1.0 \mathrm{~B}$ & $\mathrm{nd}$ & $0.5 \mathrm{~A}$ \\
DOR-Psp-PS & $9.7 \mathrm{E}$ & $\mathrm{nd}$ & $0.8 \mathrm{~B}$ \\
\hline
\end{tabular}

${ }^{a}$ Data are the mean of three independent experiments: column means followed by the same upper case letter are not significantly different $(P \leq 0.05) .{ }^{b}$ nd, not detected.

exhibited sigmoidal dose-response curves from which the inhibitory concentrations leading to $50 \%$ of germination inhibition $\left(\mathrm{IC}_{50}\right.$ ) were calculated (3.6 and $2.7 \mathrm{~g} \mathrm{~kg}^{-1}$ soil for Lepidium sativum and Lactuca sativa, respectively) (Figure 2). The degree of deviation from the fitting curves was highest with free mycelium of Phlebia sp.

Effect of Fungal Growth on Structural Changes and Carbon Pools in DOR. On the basis of the limited impact of some treatments on both dephenolization and detoxification, investigations on possible structural changes and shifts in the relative abundances of carbon pools in DOR were limited to only abiotic controls and to experiments conducted with immobilized fungal inocula.

TMAH-Py-GC MS of DOR abiotic control yielded more than 50 fragments, most of which were methyl ethers and esters of carbohydrates, fatty acids, and aromatics. The majority of these fragments were identified, as shown in Figure 3A, and found to be aromatic compounds. Among them, 1,4-dimethoxybenzene and 1,2,4-trimethoxybenzene were dominant; these compounds, however, have been shown to derive from both lignin and cellulose thermochemolysis (18). On the other hand, the major aromatic fragments unambiguously derived from lignin were 3 , 4-dimethoxybenzoic acid methyl ester $(2.7 \%)$ and 3,4-dimethoxystyrene $(1.6 \%)$. The relative abundances of lignin-related 


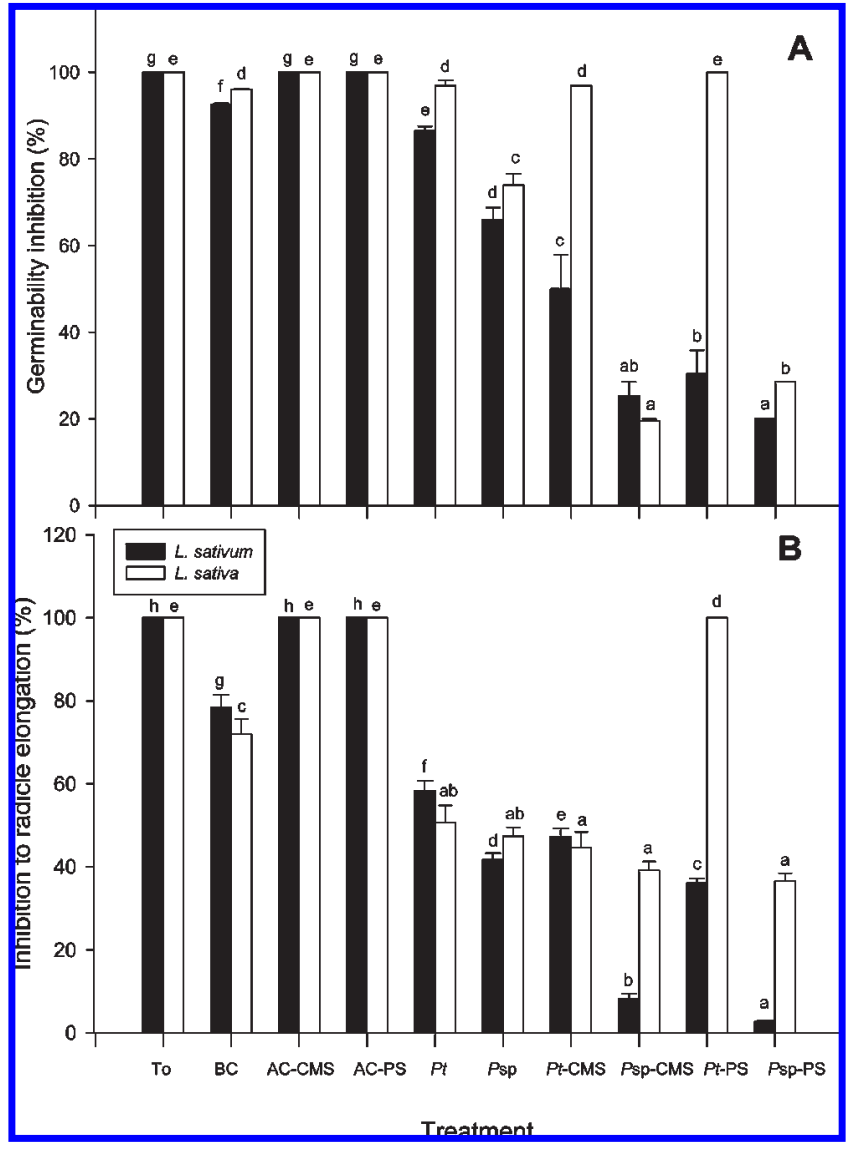

Figure 1. Percent inhibition of germinability $(\mathbf{A})$ and radicle elongation $(\mathbf{B})$ in Lepidium sativum (black bars) and Lactuca sativa (white bars) seedlings grown at $27^{\circ} \mathrm{C}$ for $48 \mathrm{~h}$ in quartz sand treated with $5 \%(\mathrm{w} / \mathrm{w})$ : DOR at start (t0); biotic control of DOR (BC); abiotic control of DOR added with corn maize stalks (AC-CMS) and the same waste incubated with either CMSimmobilized $P$. tigrinus or Phlebia sp. (Pt-CMS and Psp-CMS, respectively); abiotic control treated with polyurethane sponge (AC-PS) and the same waste incubated with PS-immobilized P. tigrinus and Phlebia sp. (PtPS and Psp-PS, respectively). Values are the means of three independent experiments, and error bars indicate standard deviations. Statistical pairwise multiple comparisons of data were carried out by the Tukey test: for each plant species, mean values with the same letter are not significantly different $(P \leq 0.05)$.

fragments were significantly affected by the fungal treatment, as exemplified by the pyrogram of DOR colonized by CMSimmobilized $P$. tigrinus (Figure 3B).

Regardless of the carrier, the abiotic controls of DOR exhibited similar percentages of $\mathrm{S}, \mathrm{G}$, and $\mathrm{P}$ subunits, in the ranges $3.1-3.2,9.9-10.7$, and $6.3-6.7 \%$, respectively (Table 5). In the same controls, $\mathrm{S} / \mathrm{G},(\mathrm{Ac} / \mathrm{Ad})_{\mathrm{G}}$, and $(\mathrm{Ac} / \mathrm{Ad})_{\mathrm{S}}$ did not significantly differ from one another. Irrespective of the fungus, the relative percent abundances of lignin subunits were significantly modified: most relevant changes were observed for $\mathrm{G}$ and $\mathrm{S}$ units, the abundances of which were markedly increased. However, $\mathrm{S} / \mathrm{G}$ ratios in fungal microcosms did not significantly differ from those of the relative abiotic controls with the only exception of CMsupported Phlebia sp. (0.54 \pm 0.02 vs $0.30 \pm 0.03$, respectively) (Table 5). The $(\mathrm{Ac} / \mathrm{Ad})_{\mathrm{S}}$ ratios of abiotic controls were generally lower than those of the waste that underwent fungal treatment irrespective of both the fungus and the inoculum carrier; similar results were observed for the $(\mathrm{Ac} / \mathrm{Ad})_{\mathrm{G}}$ ratio with the exception of the waste incubated with PS-supported P. tigrinus (Table 5).

PCA performed to analyze TMAH-Py-GC MS showed that around $77 \%$ of variability was explained by the first two principal

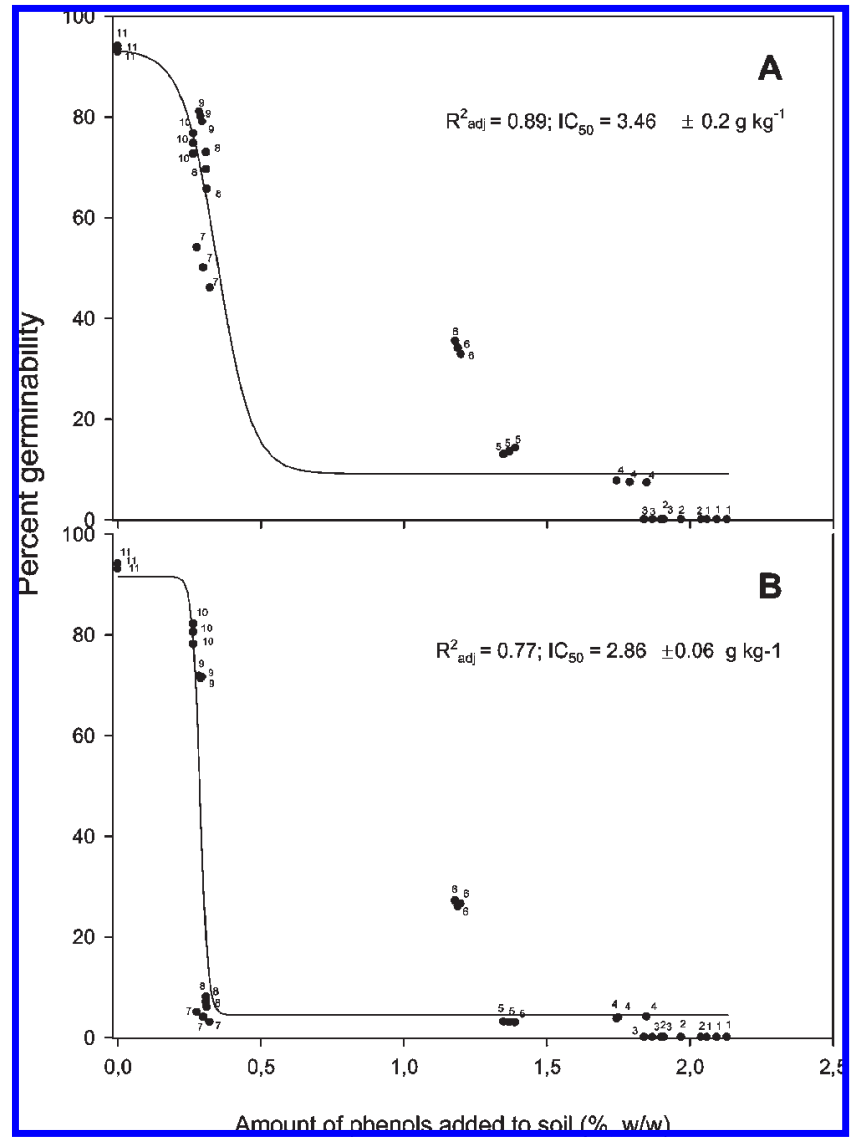

Figure 2. Correlation between the amount of total phenols added with the waste and Lepidium sativum (A) and Lactuca sativa (B) seed germination. To each data point, an Arabic number letter has been assigned to express the related treatment: (1) DOR at start; (2) abiotic control with CMS; (3) abiotic control with PS; (4) biotic control; (5) DOR incubated with free mycelium of $P$. tigrinus; (6) DOR incubated with free mycelium of Phlebia sp.; (7) DOR incubated with CMS-immobilized mycelium of $P$. tigrinus; (8) DOR incubated with CMS-immobilized mycelium of Phlebia sp.; (9) DOR incubated with PS-immobilized mycelium of $P$. tigrinus; (10) DOR incubated with PS-immobilized mycelium of Phlebia sp.; (11) distilled water control. Data are expressed in grams of phenols added to $100 \mathrm{~g}$ of growth substrate.

components (53.7 and 23.3\%, respectively) (Figure 4). Hotelling of scores showed the absence of outliers and, in addition, the observations were clearly separated in different quadrants according to the treatment typology (Figure 4A). In particular, the waste at start and the two abiotic controls were located in the upper and lower right quadrants, respectively. Computation of the contribution of the variables in the loadings plot (Figure 4B) showed that the $\mathrm{G} \%, \mathrm{~S} \%$ and the $\mathrm{S} / \mathrm{G}$ ratio had the greatest impact on variability along the first component and $\mathrm{P} \%$ and $\mathrm{G}_{\mathrm{n}} \%$ along the second one (data not shown).

With the only exception of PS-immobilized Phlebia sp., the most relevant impact of fungi on DOR carbon pools was a dramatic increase in the amount of TEC (Table 6). Fractionation and subsequent purification and quantitation of TEC fractions showed low relative abundance of humic substances $\left(\mathrm{C}_{\mathrm{HA}}+\mathrm{FA}\right)$. $\mathrm{C}_{\mathrm{HA}}$ was significantly higher than the respective abiotic control only in PS-immobilized P. tigrinus cultures (126 vs $113 \mathrm{mg} \mathrm{g}^{-1}$, respectively). Despite the low representativeness of $\mathrm{C}_{\mathrm{HA}}+\mathrm{FA}$ in TEC, their absolute amounts were generally higher in fungal cultures than in abiotic controls of DOR except for PS-immobilized Phlebia sp. (Table 6). To obtain a synoptic and overall indication of the fungal impact on the evolution of organic 


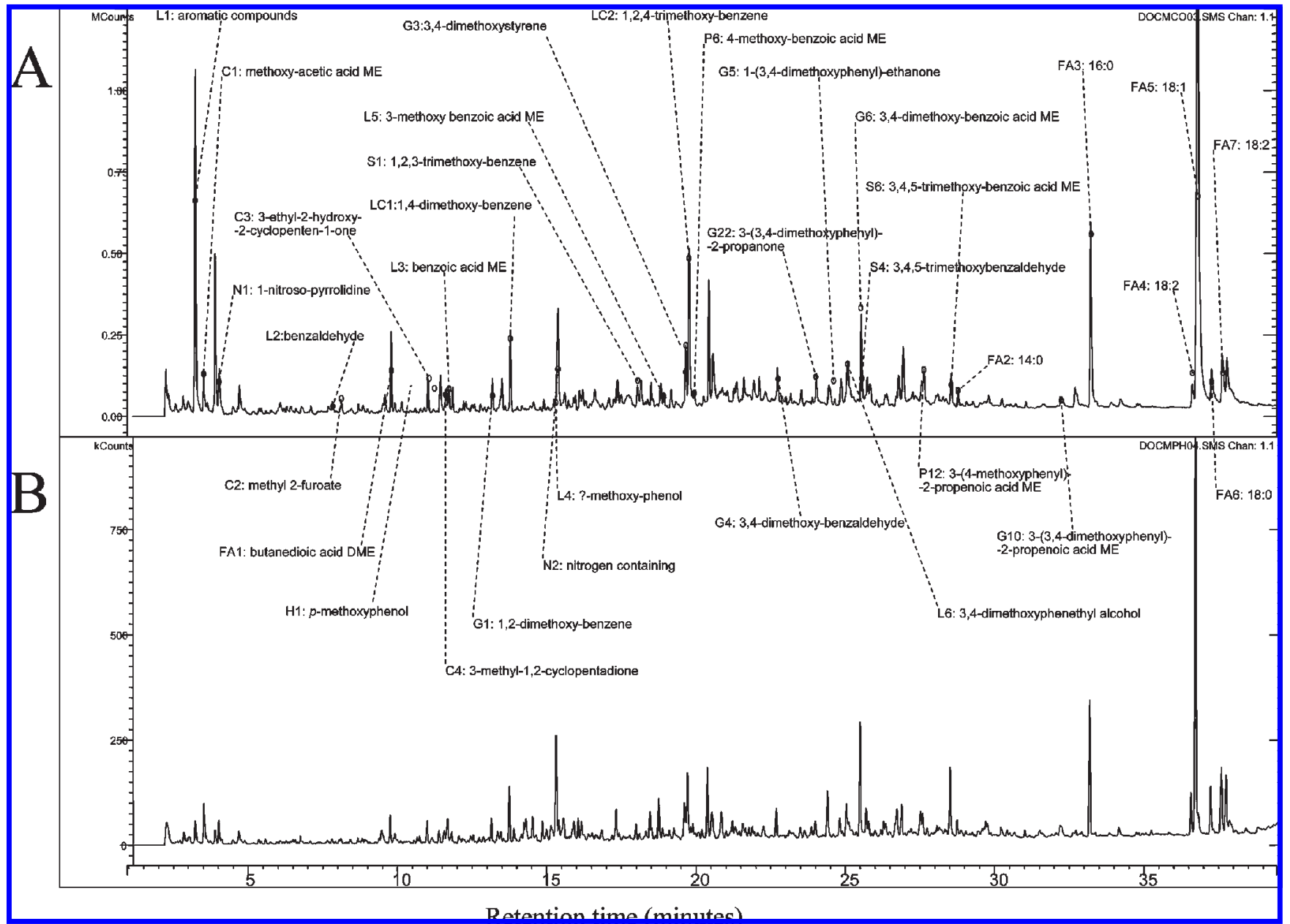

Figure 3. Pyrograms of DOR abiotic control added with corn maize stalks $(\mathbf{A})$ and after 4 weeks of treatment at $28^{\circ} \mathrm{C}$ with $\mathrm{CMS}$-immobilized $P$. tigrinus $(\mathbf{B})$. For details relative to peak labels, please see Materials and Methods. "LC" indicates those compounds that might derive from both lignin and cellulose (18).

Table 5. Relative Percent Abundances of Syringyl (S), Guaiacyl (G), and p-Hydrophenyl (P) Units and Syringyl/Guaiacyl (S/G) and Acid/Aldehyde Ratios [(Ad/Al) and $\left.(\mathrm{Ad} / \mathrm{Al})_{S}\right]$ in Bulk DOR Colonized for 4 Weeks at $28^{\circ} \mathrm{C}$ by Panus tigrinus or Phlebia sp. Supported either on Chopped Maize Stalks (CMS) or on Polyurethane Sponge (PS) and in Its Relative Abiotic Controls

\begin{tabular}{|c|c|c|c|c|c|c|c|}
\hline \multirow[b]{2}{*}{ parameter $^{a}$} & \multirow[b]{2}{*}{ DOR at start } & \multicolumn{2}{|c|}{ abiotic controls with } & \multicolumn{2}{|c|}{ Panus tigrinus supported on } & \multicolumn{2}{|c|}{ Phlebia sp. supported on } \\
\hline & & CMS & PS & $\mathrm{CM}$ & PS & $\mathrm{CM}$ & PS \\
\hline $\mathrm{G} \%^{b}$ & $15.3 \mathrm{AB}$ & $9.9 \mathrm{~A}$ & $10.7 \mathrm{~A}$ & $15.0 \mathrm{AB}$ & $22.3 B$ & $19.1 \mathrm{~B}$ & $16.9 B$ \\
\hline $\mathrm{P} \%^{b}$ & $17.0 \mathrm{~B}$ & $6.3 \mathrm{~A}$ & $6.7 \mathrm{~A}$ & $5.9 \mathrm{~A}$ & $8.1 \mathrm{~A}$ & $10.2 \mathrm{~A}$ & $7.4 \mathrm{~A}$ \\
\hline $\mathrm{S} \%^{b}$ & $2.9 \mathrm{~A}$ & $3.1 \mathrm{~A}$ & $3.2 \mathrm{~A}$ & $6.0 \mathrm{~B}$ & $9.1 \mathrm{C}$ & $10.3 \mathrm{C}$ & $6.8 \mathrm{~B}$ \\
\hline $\mathrm{G}_{n} \%^{\mathrm{c}}$ & $43.5 \mathrm{~A}$ & $51.2 \mathrm{~B}$ & $52.0 \mathrm{~B}$ & $55.5 \mathrm{~B}$ & $56.6 \mathrm{~B}$ & $48.4 \mathrm{AB}$ & $54.5 \mathrm{~B}$ \\
\hline $\mathrm{P}_{\mathrm{n}} \%^{\mathrm{c}}$ & $48.2 \mathrm{C}$ & $32.9 \mathrm{~B}$ & $32.6 \mathrm{~B}$ & $21.9 \mathrm{~A}$ & $20.3 \mathrm{~A}$ & $25.6 \mathrm{~A}$ & $23.7 \mathrm{~A}$ \\
\hline $\mathrm{S}_{\mathrm{n}} \%^{\mathrm{c}}$ & $8.3 \mathrm{~A}$ & $15.8 \mathrm{~B}$ & $15.4 \mathrm{~B}$ & $22.6 \mathrm{C}$ & $23.1 \mathrm{CD}$ & $26.0 \mathrm{D}$ & $21.9 \mathrm{C}$ \\
\hline$S / G$ & $0.20 \mathrm{~A}$ & $0.31 \mathrm{~B}$ & $0.30 \mathrm{~B}$ & $0.41 \mathrm{C}$ & $0.41 \mathrm{C}$ & $0.54 \mathrm{D}$ & $0.40 \mathrm{C}$ \\
\hline$(\mathrm{Ac} / \mathrm{Ad})_{\mathrm{G}}$ & $3.95 B$ & $2.39 \mathrm{~A}$ & $2.48 \mathrm{~A}$ & $3.36 \mathrm{AB}$ & $2.86 \mathrm{~A}$ & $3.46 \mathrm{AB}$ & $5.61 \mathrm{C}$ \\
\hline$(\mathrm{Ac} / \mathrm{Ad})_{\mathrm{S}}$ & $0.32 \mathrm{~A}$ & $0.95 \mathrm{AB}$ & $1.35 \mathrm{AB}$ & $2.13 B$ & $1.79 \mathrm{~B}$ & $2.3 \mathrm{~B}$ & $5.60 \mathrm{C}$ \\
\hline
\end{tabular}

${ }^{a}$ Data are the mean of triplicate runs and row means followed by the same upper case letter did not significantly differ $(P \leq 0.05) .{ }^{b}$ Data calculated with respect to the total peak areas. ${ }^{c}$ Data calculated with respect to the sum of peak areas of $P, G$, and $S$ subunits.

matter, widely accepted descriptors of the humification process, relating humic substances to different $\mathrm{C}$ pools, were calculated. Table 6 shows that PS-immobilized Phlebia sp. was the sole condition where the value of $\mathrm{DH}$, which relates $\mathrm{C}_{\mathrm{HA}}+\mathrm{FA}$ to TEC, was significantly higher than that of the respective abiotic control. By contrast, both $\mathrm{HR}$ and $\mathrm{HI}$, relating, respectively, $\mathrm{C}_{\mathrm{HA}}$ and $\mathrm{C}_{\mathrm{HA}+\mathrm{FA}}$ to TOC, were higher in fungal cultures than in abiotic counterparts (Table 6).

\section{DISCUSSION}

White-rot fungi are very attractive for decontamination and detoxification purposes $(6,7)$; their large-scale application, however, is hampered by several technical constraints, including inocula formulation and mode of application (19). High amounts of inocula $(10-20 \%, \mathrm{w} / \mathrm{w})$, in fact, were needed when free mycelia were incorporated into solid matrices, probably due to friction during mixing (19). As a consequence, different types of carriers to be used in mycoaugmentation have been suggested (20-22).

Although the recalcitrance of DOR is being increasingly identified as one of the major factors hindering microbial approaches aimed at its upgrading $(1,6,7)$, the technical aspects associated with fungal inoculum formulation have not yet been given the right consideration. On the other hand, both bioconversion and decontamination of a given solid matrix depend on the 
survival and activity of inoculated fungi (21). Spores or mycelial fragments have been reported to be more sensitive to growth inhibition by phenols, such as pentachlorophenol (PCP), than immobilized mycelia (21). The susceptibility of fungi to concentration-dependent growth inhibition by phenols has long been

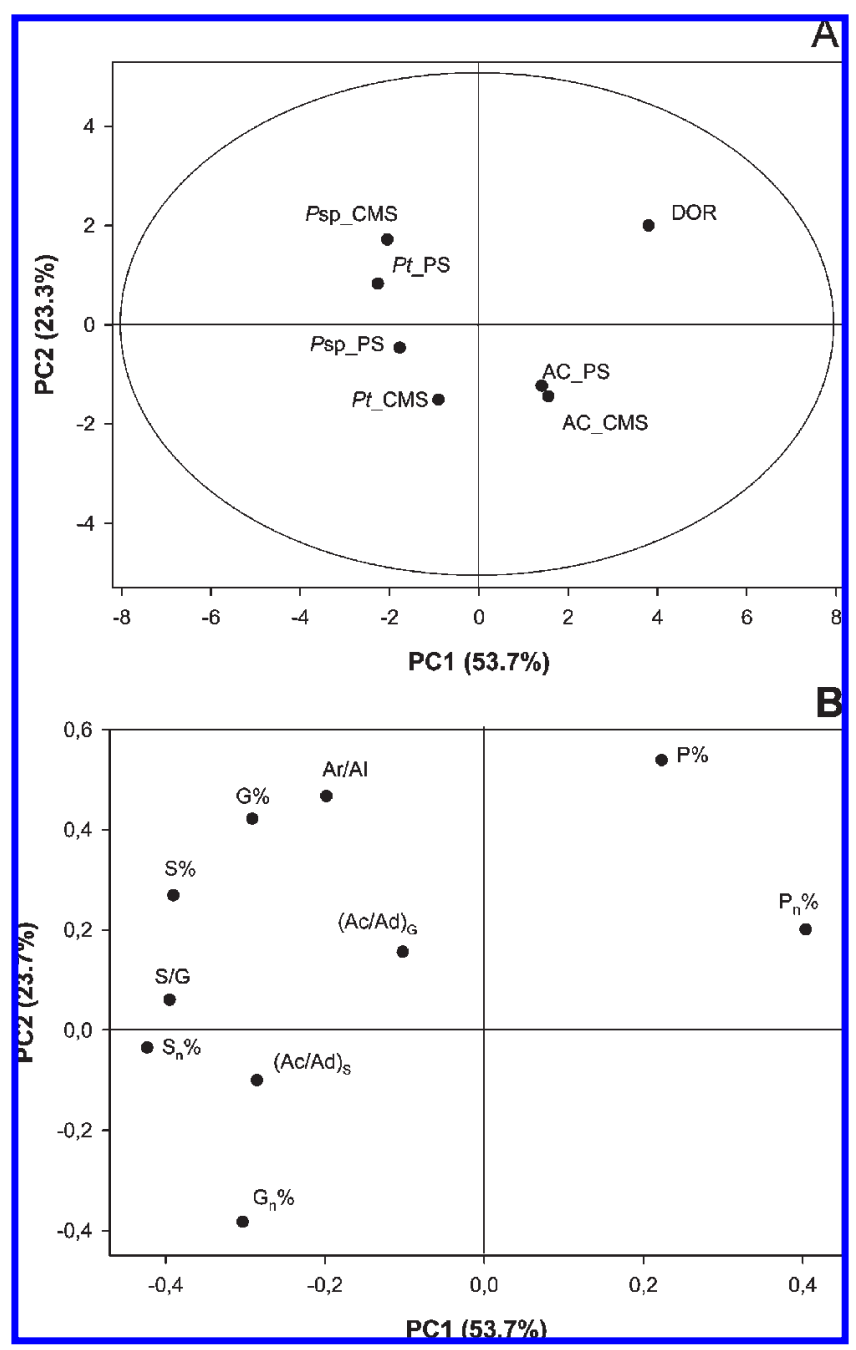

Figure 4. Principal component analysis of TMAH-py-GC MS data showing scores (A) and loadings (B) plots. Percent variability explained by each principal component $(\mathrm{PC})$ is shown in parentheses after each axis legend. Abbreviations: DOR, waste at start; AC_CMS abiotic control with corn maize stalks; AC_PS, abiotic control with polyurethane sponge; Pt_CMS and Psp_CMS, $P$. tigrinus and Phebia sp. immobilized onto corn maize stalks, respectively; Pt_PS and Psp_PS, P. tigrinus and Phebia sp. immobilized onto polyurethane sponge. Please see Table 5 for abbreviations used in plot $\mathbf{B}$. known (23) and should not be neglected when phenol-rich materials such as DOR are considered. In this respect, the different growth responses observed in the present study with free and immobilized inocula might, at least partially, be due to the carrier protective action as also observed by Leštan et al. (21) and Ford et al. (22). In addition, natural immobilization supports, such as lignocellulosic materials, providing nutrients to the mycelial coat might give the fungi an initial competitive advantage over free inocula, leading to increased survival and growth $(21,22)$. This might explain why in the present study the fungal metabolic activity was highest with CMS-immobilized inocula, whereas with the inert PS, FMIs of immobilized fungi did not differ from those of free mycelia. Use of lignocellulosic substrates coated with alginate-entrapped mycelia conferred the inoculated fungi high antagonistic potential toward indigenous microflora and resistance to growth-inhibiting contaminants likely due to the availability of nutrients arising from the underlying support $(20,21)$.

In the present study, the use of immobilized inocula led to increased phenols removal with respect to free inocula, regardless of both the fungus and the carrier. However, with regard to DE, a parameter whereby the amounts of phenols removed are normalized to the same amount of biomass, only $P$. tigrinus increased its efficiency with immobilization.

Another interesting aspect associated with the physiology of a phenol-degrading organism is degradation selectivity. In this respect, Phlebia sp. exhibited higher DS than $P$. tigrinus with the sole exception of the CMS-immobilized formulate. It is interesting to note that the highest DS values were obtained with immobilized inocula where activity levels of enzymes putatively involved in the oxidation of phenols were significantly higher than the respective free inocula (Tables 2 and 4 ). In this regard, the expression of both laccase and $\mathrm{MnP}$ has been reported to be affected by the composition of lignocellulosic mixtures employed in inocula formulation (22). Moreover, laccase has been shown to be actively involved in phenols removal from DOR (24).

Phytotoxic effects of olive-mill wastes have been suggested to be due to high salt content, relatively low $\mathrm{pH}$, and the presence of other organic components, such as fatty acids (5); phenols, however, are kept as primary determinants of the phytotoxicity of olive residues $(1,2,6,11)$.

The specific mechanisms underlying the phytotoxic action of phenols have not been fully elucidated. However, their toxicity has been attributed to a narcosis mode of action, mainly ascribable to their non-covalent interaction at the membrane level (25). In the present study, immobilized inocula were more effective than free mycelia in reducing phytotoxicity of DOR toward Lepidium sativum. On an overall basis, however, Phlebia sp. was more effective than $P$. tigrinus; in fact, the latter did not alleviate the DOR phytoxicity toward Lactuca sativa. This might be due to the markedly higher efficiency of Phlebia sp. in reducing

Table 6. Total Organic Carbon (TOC), Total Extractable Carbon (TEC), Humic and Fulvic Acids Carbon ( $\mathrm{C}_{\mathrm{HA}}$ and $\mathrm{C}_{\mathrm{FA}}$, Respectively), Degree of Humification (DH), Humification Ratio (HR), and Humification Index (HI) in DOR at Start $\left(t_{0}\right)$ and in the Same Waste That Had Been Incubated with $P$. tigrinus and Phlebia sp. Previously Immobilized onto Chopped Maize Stalks or Polyurethane Sponge (Pt-CMS and Psp-CMS, Respectively, and Pt-PS and Psp-PS, Respectively) and in the Relative Abiotic Controls (AC-CMS and AC-PS)

\begin{tabular}{|c|c|c|c|c|c|c|c|c|}
\hline sample & $\mathrm{TOC}^{a}(\mathrm{mg} / \mathrm{g})$ & $\mathrm{TEC}^{a}(\mathrm{mg} / \mathrm{g})$ & $\mathrm{CHA}_{\mathrm{H}}{ }^{a}(\mathrm{mg} / \mathrm{g})$ & $\mathrm{C}_{\mathrm{FA}}{ }^{a}(\mathrm{mg} / \mathrm{g})$ & $\mathrm{C}_{\mathrm{HA}+\mathrm{FA}}{ }^{a}(\mathrm{mg} / \mathrm{g})$ & $\mathrm{DH}^{a}(\%)$ & $\mathrm{HR}^{a}(\%)$ & $\mathrm{HI}^{a}(\%)$ \\
\hline $\mathrm{DOR} t_{0}$ & $495 C$ & $203 \mathrm{~A}$ & $99.3 \mathrm{~A}$ & $29.3 \mathrm{~A}$ & $128.5 \mathrm{~A}$ & $63.3 \mathrm{C}$ & $26.0 \mathrm{~A}$ & $20.1 \mathrm{~A}$ \\
\hline AC-CMS & $479 B$ & $214 \mathrm{~A}$ & $101.5 \mathrm{~A}$ & $29.1 \mathrm{~A}$ & $130.7 \mathrm{~A}$ & $61.1 \mathrm{C}$ & $27.3 \mathrm{~A}$ & $21.2 \mathrm{~A}$ \\
\hline$P t-\mathrm{CMS}$ & $467 \mathrm{~A}$ & $439 \mathrm{C}$ & $110.4 \mathrm{~A}$ & $46.6 \mathrm{C}$ & $157.1 \mathrm{~B}$ & $35.8 \mathrm{~A}$ & $33.6 \mathrm{C}$ & $23.6 \mathrm{~B}$ \\
\hline Psp-CMS & $452 \mathrm{~A}$ & $420 \mathrm{C}$ & $107.2 \mathrm{~A}$ & $48.3 \mathrm{C}$ & $155.4 \mathrm{~B}$ & $37.0 \mathrm{~A}$ & $34.4 \mathrm{C}$ & 23.7 B \\
\hline AC-PS & $487 \mathrm{~B}$ & $263 B$ & $112.8 \mathrm{~A}$ & $27.9 \mathrm{~A}$ & $140.5 \mathrm{~A}$ & $53.4 \mathrm{~B}$ & $28.7 \mathrm{~B}$ & $23.2 \mathrm{~B}$ \\
\hline Pt-PS & $466 \mathrm{~A}$ & $441 \mathrm{C}$ & $125.7 \mathrm{~B}$ & $24.7 \mathrm{~A}$ & $150.6 \mathrm{~B}$ & $34.1 \mathrm{~A}$ & $32.3 \mathrm{C}$ & $27.0 \mathrm{C}$ \\
\hline Psp-PS & $479 B$ & $226 \mathrm{~A}$ & $98.8 \mathrm{~A}$ & $37.4 \mathrm{~B}$ & $136.0 \mathrm{~A}$ & $60.2 \mathrm{C}$ & $28.4 \mathrm{~B}$ & $20.6 \mathrm{~A}$ \\
\hline
\end{tabular}

${ }^{a}$ Data are the mean of three independent experiments: column means followed by the same upper case letter are not significantly different $(P \leq 0.05)$. 
ethyl acetate-extractable phenols (Tables $\mathbf{2}$ and $\mathbf{3}$ ). This fraction mainly encompasses the waste's monomeric phenols, which, by virtue of their reduced molecular weight and lipophilicity, have better access to the plant membrane than the polymeric ones (11). This hypothesis is supported by a recent study reporting that Lepidium sativum germinability was not negatively affected by the residual aqueous fraction of DOR obtained through extensive ethyl acetate extraction (2). Moreover, a clear relationship between trans-cinnamic derivatives, such as p-coumaric acid, and abscissic acid (ABA) on the inhibition of Lactuca sativa germination has been reported (26). With this specific regard, P. tigrinus was significantly less effective than Phlebia sp. in the removal of p-coumaric acid from DOR. In addition, $P$. tigrinus actively produced ABA in olive-mill waste-based medium (27). The biological conversion of lignocellulosic residues by white-rot fungi leads to the formation of humic-like substances, the amount of which depends on the balance between polymerization and depolymerization reactions (28) and on the variable degradation ability of these organisms toward humic acids (29). In the present study, an overall increase in the amount of $\mathrm{C}_{\mathrm{HA}}+\mathrm{FA}$ was found in DOR that had been incubated with immobilized fungi with respect to abiotic controls; this effect, however, was associated with a concomitant drastic increase in the amount of TEC leading to lower DH values, thus indicating that the humification process in DOR was just at its early stage. This was also confirmed by the higher abundance of $\mathrm{C}_{\mathrm{FA}}$ than $\mathrm{C}_{\mathrm{HA}}$ and by the low percent abundance of the latter in TEC. This indication was supported by TMAH-Py-GC MS analyses of the waste, which showed that the $\mathrm{S} / \mathrm{G}$ ratio did not change upon fungal treatments, although it was expected to be decreased in the presence of an extensive delignification $(12,13)$. However, the generalized increase in the $(\mathrm{Ac} / \mathrm{Ad})_{\mathrm{S}}$ and, in some cases, the $(\mathrm{Ac} / \mathrm{Ad})_{\mathrm{G}}$ ratio in $\mathrm{DOR}$ incubated with fungi suggested the occurrence of oxidative cleavage of the $\mathrm{C}_{\alpha}-\mathrm{C}_{\beta}$ bonds in the propenyl side chain of lignin subunits; this is one of the main mechanisms involved in lignin depolymerization (13). Interestingly, the waste exhibited a significant presence of $\mathrm{H}$ monolignols and very low $\mathrm{S} / \mathrm{G}$ ratio. The high abundance of $\mathrm{P}$ subunits in DOR is interesting and anomalous, because it arises from Olea europea L., a member of dicotyledonous angiosperms, the lignins of which are mainly composed by $\mathrm{G}$ and $\mathrm{S}$ moieties $(30)$. The $\mathrm{S} / \mathrm{G}$ ratio has been suggested to be an important determinant for the susceptibility of a lignocellulosic material to biodegradation, the extent of which increases as the ratio increases (13). The rationale is that the $\mathrm{S}$ units, besides being characterized by redox potentials lower than the $\mathrm{G}$ units, are connected via relatively labile ether bonds in lignin. Conversely, $\mathrm{G}$ monolignols tend to form highly condensed lignin substructures with a predominance of both stable biphenyl and other carbon-carbon linkages, which are less susceptible to biodegradation (30). Therefore, the widely reported recalcitrance of the waste to biological degradation (1) might be explained both by these structural characteristics and by the large abundance of endocarp fragments, where the majority of lignin is located, with low surface area exposed to microbial attack.

\section{ABBREVIATIONS USED}

$(\mathrm{Ad} / \mathrm{Al})_{\mathrm{G}}$, guaiacyl acid/aldehyde ratio; $(\mathrm{Ad} / \mathrm{Al})_{\mathrm{S}}$, syringyl acid/aldehyde ratio; $\mathrm{Ar} / \mathrm{Al}$, aromatic/aliphatic ratio; AWSP, acetone/water-soluble phenols; $\mathrm{C}_{\mathrm{FA}}$, fulvic acid carbon; $\mathrm{C}_{\mathrm{HA}}$, humic acid carbon; CMS, chopped maize stalks; DE, dephenolization efficiency; DH, degree of humification; DOR, dry olivemill residue; DS, dephenolization selectivity; EAEP, ethyl acetate-extractable phenols; FA, fatty acids; FMI, fungal metabolic index; G, guaiacyl subunits; P, p-hydroxyphenyl subunits; HI, humification index; $\mathrm{HR}$, humification ratio; $\mathrm{IC}_{50}$, concentration required for $50 \%$ germinability inhibition; $\mathrm{MnP}$, manganese peroxidase; OM, organic matter; PCA, principal component analysis; PS, polyurethane sponge; RP-HPLC, reversed-phase high-performance liquid chromatography; S, syringyl subunits; $\mathrm{S} / \mathrm{G}$, syringyl/guaiacyl ratio; TEC, total extractable carbon; TOC, total organic carbon; TMAH, tetramethylammonium hydroxide; TPEP, two-phase extraction process; WRF, whiterot fungi.

\section{LITERATURE CITED}

(1) Roig, A.; Cayuela, M. L.; Sánchez-Monedero, M. A. An overview on olive mill wastes and their valorisation methods. Waste Manag. 2006, 26, 960-969.

(2) Aranda, E.; García-Romera, I.; Ocampo, J. A.; Carbone, V.; Mari, A.; Malorni, A.; Sannino, F.; De Martino, A.; Capasso, R. Chemical characterization and effects on Lepidium sativum of the native and bioremediated components of dry olive mill residue. Chemosphere 2007, 69, 229-239.

(3) Cayuela, M. L.; Sánchez-Monedero, M. A.; Roig, A. Evaluation of two different aeration systems for composting two-phase olive mill wastes. Process Biochem. 2006, 41, 616-623.

(4) Sánchez-Monedero, M. A.; Cayuela, M. L.; Mondini, C.; Serramia, N.; Roig, A. Potential of olive mill wastes for soil C sequestration. Waste Manag. 2008, 28, 767-773.

(5) González, M. D.; Moreno, E.; Quevedo-Sarmiento, J.; RamosCormenzana, A. Studies on antibacterial activity of waste waters from olive oil mills (alpechín): inhibitory activity of phenolic and fatty acids. Chemosphere 1990, 20, 423-432.

(6) Linares, A.; Caba, J. M.; Ligero, F.; de la Rubia, T.; Martínez, J. Detoxification of semisolid olive-mill wastes and pine-chip mixtures using Phanerochaete flavido-alba. Chemosphere 2003, 51, 887-891.

(7) Sampedro, I.; Marinari, S.; D’Annibale, A.; Grego, S.; Ocampo, J. A.; García-Romera, I. Organic matter evolution and partial detoxification in two-phase olive mill waste colonized by white-rot fungi. Int. Biodeterior. Biodegr. 2007, 60, 116-125.

(8) Leonardi, V.; Giubilei, M. A.; Federici, E.; Spaccapelo, R.; Šašek, V.; Novotny, C.; Petruccioli, M.; D’Annibale, A. Mobilizing agents enhance fungal degradation of polycyclic aromatic hydrocarbons and affect diversity of indigenous bacteria in soil. Biotechnol. Bioeng. 2008, 101, 273-285.

(9) Cavani, L.; Ciavatta, C.; Gessa, C. Identification of organic matter from peat, leonardite and lignite fertilisers using humification parameters and electrofocusing. Bioresour. Technol. 2003, 86, 45-52.

(10) D'Annibale, A.; Ricci, M.; Quaratino, D.; Federici, F.; Fenice, M. Panus tigrinus efficiently removes colour, organic load and phenols from olive-mill wastewater. Res. Microbiol. 2004, 155, 596-603.

(11) Casa, R.; D’Annibale, A.; Pieruccetti, F.; Stazi, S. R.; Giovannozzi Sermanni, G.; Locascio, B. Reduction of the phenolic components in olive-mill wastewater by an enzymatic treatment and its impact on durum wheat (Triticum durum Desf.) germinability. Chemosphere 2003, 50, 959-966.

(12) Steffen, K. T.; Cajthaml, T.; Snajdr, J.; Baldrian, P. Differential degradation of oak (Quercus petraea) leaf litter by litter-decomposing basidiomycetes. Res. Microbiol. 2007, 158, 447-455.

(13) Vane, C. H.; Martin, S. C.; Snape, C. E.; Abbott, G. D. Degradation of lignin in wheat straw during growth of the oyster mushroom (Pleurotus ostreatus) using off-line thermochemolysis with TMAH and solid-state ${ }^{13} \mathrm{C}$ NMR. J. Agric. Food Chem. 2001, 49, 2709-2716.

(14) Boyle, D. Nutritional factors limiting the growth of Lentinula edodes and other white-rot fungi in wood. Soil Biol. Biochem. 1998, 30, 817-823.

(15) Espín, C. J.; Tudela, J.; García-Cánovas, F. 4-Hydroxyanisole: the most suitable monophenolic substrate for determining spectrophotometrically the monophenolase activity of polyphenol oxidase from fruits and vegetables. Anal. Biochem. 1998, 259, 118-126.

(16) Zucconi, F.; Pera, A.; Forte, M.; De Bertoldi, M. Evaluating toxicity of immature compost. Biocycle 1981, 22, 524-527.

(17) MacGregor, J. F.; Kourti, T. Statistical process control of multivariate processes. Control Eng. Practice 1995, 3, 403-421. 
(18) Chefetz, B.; Chen, Y.; Clapp, C. E.; Hatcher, P. G. Characterization of organic matter in soils by thermochemolysis using tetramethylammonium hydroxide (TMAH). Soil Sci. Soc. Am.J. 2000, 64, $583-589$.

(19) Lamar, R. T.; White, R. B. Mycoremediation-commercial status and recent developments. In Ex Situ Biological Treatment Technologies; Magar, A., Von Fahnestock, F. M., Eds.; Battelle Press: Columbus, OH, 2001; Vol. 6, pp 263-278.

(20) Leštan, D.; Lamar, R. T. Development of fungal inocula for bioaugmentation of contaminated soils. Appl. Environ. Microbiol. 1996, 62, 2045-2052.

(21) Leštan, D.; Leštan, M.; Chapelle, J. A.; Lamar, R. T. Biological potential of fungal inocula for bioaugmentation of contaminated soils. J. Ind. Microbiol. 1996, 16, 286-294.

(22) Ford, C. I.; Walter, M.; Northcott, G. L.; Di, H. J.; Cameron, K. C.; Trower, T. Fungal inoculum properties: extracellular enzyme expression and pentachlorophenol removal in highly contaminated field soils. J. Environ. Oual. 2007, 36, 1599-1608.

(23) Buswell, J. A.; Eriksson, K. E. L. Effect of lignin-related phenols and their methylated derivatives on the growth of eight white-rot fungi. World J. Microbiol. Biotechnol. 1994, 10, 169-174.

(24) Aranda, E.; Sampedro, I.; Ocampo, J. A.; Garcia-Romera, I. Phenolic removal of olive-mill dry residues by laccase activity of white-rot fungi and its impact on tomato plant growth. Int. Biodeterior. Biodegr. 2006, 58, 176-179.
(25) Wang, X.; Wang, Y.; Chunsheng, Y.; Wang, L.; Han, S. Mechanismbased quantitative structure-phytotoxicity relationships comparative inhibition of substituted phenols on root elongation of Cucumis sativus. Arch. Environ. Contam. Toxicol. 2002, 42, 29-35.

(26) Li, H.; Inoue, M.; Nishimura, H.; Mizutani, J.; Tsuzuki, E. Interactions of trans-cinnamic, its related phenolic allelochemicals, and abscissic acid in seedling growth and seed germination of lettuce. J. Chem. Ecol. 1993, 19, 1775-1787.

(27) Ozcan, B.; Topcuoglu, S. F. GA3, ABA and cytokinin production by Lentinus tigrinus and Laetiporus sulphureus fungi cultured in the medium of olive oil mill waste. Turkish J. Biol. 2001, 25, 453-462.

(28) Reid, I. D. Fate of residual lignin during delignification of kraft pulp by Trametes versicolor. Appl. Environ. Microbiol. 1988, 64, 2117-2125.

(29) Dehorter, B.; Blondeau, R. Extra-cellular enzyme activities during humic acid degradation by white-rot fungi Phanerochaete chrysosporium and Trametes versicolor. FEMS Microbiol. Lett. 1992, 94, 209-215.

(30) Whetten, R.; MacKay, J. J.; Sederoff, R. Recent advances in understanding lignin biosynthesis. Annu. Rev. Plant Phvsiol. Plant Mol. Biol. 1998, 49, 585-609.

Received January 21, 2009. Revised manuscript received April 22, 2009. Accepted May 11, 2009. This work was financially supported in part by the Italian Ministry of Agricultural and Forest Policy (MIPAF) within the Project "VALOROLIO". 